\title{
Effects of genetic selection for fearfulness or social reinstatement behavior on adult social and sexual behavior in domestic quail (Coturnix japonica)
}

\author{
MELISSA BURNS and MICHAEL DOM JAN \\ University of Texas, Austin, Texas \\ and \\ ANDREW D. MILLS \\ Station de Recherches Avicoles, Institut National de la Recherche Agronomique \\ Centre de Tours-Nouzilly, Nouzilly, France
}

\begin{abstract}
Male quail (Coturnix japonica) were genetically selected for high or low levels of social reinstatement behavior (weighted for independence from inherent fearfulness) and high or low fearfulness (weighted for independence from social reinstatement behavior). Genetic selection was based on tests conducted during the first 10 days after hatching. Inherent fearfulness was inferred from a test of the tonic immobility response, and social reinstatement behavior was measured in a treadmill test. When tested in adulthood, males selected for high levels of social reinstatement behavior showed more social proximity behavior, shorter latencies to copulate with a female, larger numbers of copulatory responses, and greater copulatory efficiency than did males selected for low inherent fearfulness. The other genetic lines performed at intermediate levels. Thus, the effects of genetic selection extended into adulthood and influenced responses that were not in the behavioral repertoire of the birds at the time of selection. Interestingly, selection for inherent fearfulness did not necessarily disrupt sexual performance. In fact, fearfulness appeared, at least to some extent, to be conducive to the expression of male sexual behavior.
\end{abstract}

Sexual behavior has both approach and avoidance components. For successful reproduction, potential sexual partners have to be attracted to, and approach, one another. Furthermore, the tendency to approach must be stronger than the tendency to withdraw. Withdrawal may occur because of fear elicited by the other animal (which may be a rival or a predator rather than a safe sexual partner) or because of fear elicited by other cues in the situation. These considerations suggest that sexual behavior is the net result of the interaction of the defensive and sexual behavior systems.

Interactions between different systems of behavior have been investigated most extensively using the simultaneous activation paradigm. In this paradigm, the two behavior systems of interest are activated at the same time to see

\footnotetext{
The data were collected at the Institut National de la Recherche Agronomique (INRA), Centre de Tours-Nouzilly, Nouzilly, France. While collecting the data, M.B.H. was supported by a predoctoral fellowship from INRA. The collaboration between A.D.M. and M.D. was supported by a grant from the North Atlantic Treaty Organization. Preparation of the manuscript was supported by Grant MH39940 from the National Institute of Mental Health, and funding by INRA. The authors thank Jean Michel Faure for his help and encouragement during the conduct of this study. Correspondence should be addressed to M. Domjan, Department of Psychology, University of Texas, Austin, TX 78712 (e-mail: domjan@psy.utexas.edu).
}

how one system influences responses characteristic of the other.

Perhaps the most extensively investigated interactions are those between the feeding and defensive behavior systems. The defensive behavior system is typically activated in laboratory studies with the use of footshock or a conditioned stimulus previously associated with shock. In contrast, the feeding system is typically activated by providing food-deprived animals access to small portions of food contingent on an instrumental response and/or a conditioned stimulus. The common finding is that activation of the defensive behavior system (e.g., fear) suppresses food-motivated behavior (Blackman, 1977; Davis, 1968; Dickinson \& Dearing, 1979; Rescorla \& Solomon, 1967). In fact, fear tends to suppress most other forms of behavior (Jones, 1987a), with the exception of avoidance or other fear-motivated responses (Bull \& Overmier, 1968). These findings suggest that fear may also disrupt sexual behavior.

Another strategy for investigating the interaction of different systems of behavior involves genetic selection. Selected lines are powerful tools for the analysis of behavioral traits such as fearfulness (e.g., Gray, 1971). Using this methodology, changes in the animal's fear state are not induced by the presentation of a conditioned or unconditioned aversive stimulus. Rather, lines that differ in their inherent or underlying fearfulness (the propensity to be 
easily frightened) are established by genetic selection. The behavior of animals from such lines is then compared in contexts involving feeding or sexual behavior.

The present experiment was conducted to investigate the effects of inherent fearfulness and social reinstatement tendencies on male sexual behavior using the genetic selection methodology. The experiment was conducted with four genetic lines of Japanese quail. Two of the lines were selected for high or low levels of social reinstatement behavior weighted for independence from fearfulness, and the other two lines were selected for high or low fearfulness weighted for independence from social reinstatement behavior (Mills \& Faure, 1991).

For the purposes of selection, fearfulness was measured in terms of the duration of the tonic immobility (TI) response. The duration of TI is a widely used measure of inherent fearfulness, especially in domesticated birds (Gallup, 1979; Jones, 1986). Exposure to frightening procedures prolongs the TI reaction, whereas procedures that reduce fear shorten TI (Gallup, 1979; Jones, 1986, 1987a), and the duration of TI has been shown to be highly correlated with responsiveness in a variety of fear tests in Japanese quail, domestic chicks, and adult hens (Faure, 1975; Jones, 1987b; Jones \& Mills, 1983; Mills \& Faure, 1986; Suarez \& Gallup, 1981). Furthermore, genetic selection based on the duration of TI in Japanese quail has been shown to result in changes in a variety of fear-based responses. Jones, Mills, and Faure (1991), for example, found that quail selected for short tonic immobility (STI) emerged faster from a hole-in-the-wall box and showed less freezing and less suppression of vocalization and locomotion in an open field than did quail selected for long tonic immobility (LTI). Selection for STI has also been found to alter the response of quail to a restraint stressor. STI birds struggle more when restrained than do LTI birds (Jones, Mills, Faure, \& Williams, 1994). The duration of TI can therefore be considered to be a useful, if indirect, behavioral measure of the potential to react in a fearful manner.

Social reinstatement behavior was assessed in the treadmill apparatus described by Mills and Faure (1990). This apparatus was used to measure the distance run by an isolated quail chick in order to rejoin a group of conspecifics. Genetic selection based on responding in the treadmill apparatus has been found to result in general differences in sociality. Quail chicks selected for high social reinstatement (HSR) behavior in the treadmill are also faster to establish visual contact with a group of conspecifics that are housed in a restricted area of a maze-like apparatus and are more likely to move toward and remain near the other chicks than are quail selected for low social reinstatement (LSR) behavior (Launay, Mills, \& Faure, 1991). HSR chicks also peep sooner and more frequently before finding the other quail in the maze and interact with the other quail more after finding them (Launay et al., 1991). In addition, HSR chicks show greater behavioral and physiological activation than LSR chicks when they are socially isolated (Mills, Jones, Faure, \& Williams, 1993). There- fore, it can be assumed that chicks of the HSR line show higher levels of sociality than do chicks of the LSR line.

On the basis of the kinds of interactions between behavior systems that have been obtained using the simultaneous activation paradigm, one would predict that sexual behavior will be disrupted by high levels of fearfulness and enhanced by sociality. However, other considerations suggest that genetic selection for fearfulness should not disrupt sexual behavior. Fearfulness, as manifest in TI, has been considered to be an adaptive trait, because animals that show the immobility response are more likely to survive predator attack (Thompson et al., 1981). Fearfulness and fear responses presumably evolve in natural populations as predator-avoidance strategies (Faure, Jones, \& Bessei, 1983; Suarez \& Gallup, 1981). However, any increase in fitness associated with fearfulness might be offset if fearfulness unduly inhibited the expression of sexual behavior because of fear of the potential mate or the risk of attracting the attention of predators. These considerations suggest that genetic selection for fearfulness may not necessarily be accompanied by inhibition of sexual behavior. In fact, the expression of sexual behavior may well represent a balance between fearfulness and sexual motivation. Hence, genetic selection may produce results different from those predicted by the simultaneous activation paradigm.

Tests were conducted both in the home cages of the birds and in a special experimental chamber. The effects of fearfulness on sexual behavior were expected to be enhanced in the experimental chamber at least initially, because of the relative novelty of the chamber. Use of the experimental chamber also permitted us to measure social proximity behavior, an appetitive component of the sexual behavior sequence. When first placed in the experimental chamber, a male bird could see but not copulate with a female housed in an adjacent compartment. Previous studies with unselected Japanese quail have shown that, under these conditions, males suppress their crowing and approach the window through which they can see the female (Domjan \& Hall, 1986; Domjan \& Nash, 1988). After measuring the male's approach to the window on each trial, we removed the barrier between the male and female compartments and observed the copulatory behavior that ensued.

\section{METHOD}

\section{Subjects}

The subjects were from the 20th generation of lines of quail divergently selected for duration of the TI response or social reinstatement behavior. The precise history of these lines is described elsewhere (see Mills \& Faure, 1991, for details of the selection procedures and responses to the F8 generation; see Mills et al., 1994, for responses to the F16 generation). Social reinstatement behavior was assessed when the chicks were 6-8 days old using a treadmill apparatus, as described by Mills and Faure (1990). Briefly, this apparatus had a goalbox, containing 5 control line chicks, separated from a runway by a wire mesh screen. The runway was divided into three zones: a running zone proximal to the goalbox, a middle or neutral zone, and a far zone opposite the goalbox. The test started when 
a subject was placed in the center of the runway. If the chick moved toward the goalbox, the experimenter manipulated the speed of the treadmill in order to maintain the position of the subject at the start of the running zone. The distance run was recorded. If the chick moved away from the goalbox, the amount of time spent in the "far zone" was recorded. The subjects were then classified into one of two categories. The chicks that ran to maintain their position near the stimulus chicks in the goalbox were classified as high social reinstatement (HSR), and those that did not remain near the stimulus chicks were classified as low social reinstatement (LSR). At the 20th generation of selection, the mean $( \pm S D)$ distance run was $60 \mathrm{~m}( \pm 27)$ for the HSR line and $3 \mathrm{~m}( \pm 9)$ for the LSR line.

Selection for TI was done on the basis of a test conducted at 9-10 days of age. Each chick was placed on its back in a U-shaped cradle. The chicks were gently held in this position for $10 \mathrm{sec}$ and were then left unrestrained. Records were made of the number of attempts necessary to induce a period of immobility greater than $10 \mathrm{sec}$ following removal of restraint. The duration of TI was also recorded. Selection was conducted for long (LTI) or short (STI) duration of the TI reaction. At the 20 th generation of selection, the mean $( \pm S D$ ) duration of TI was $248 \mathrm{sec}( \pm 79)$ in the LTI line and $9 \mathrm{sec}$ $( \pm 16)$ in the STI line.

The birds were removed from mixed-sex brooder cages at 21 days of age and were housed in individual metal cages. Lighting was set on a 16:8-h light:dark schedule to maintain the birds in reproductive condition. The photoperiod lasted from 0400 to $2000 \mathrm{~h}$ Central European Time. Food and water were available ad lib except during testing. The sexual behavior tests started when the birds were about 90 days old.

Testing in the home cages was conducted with 8 sexually naive males and 8 sexually naive females from each of the four genetic lines. Half of these males and all of the females subsequently served in the experimental-chamber tests, together with 4 additional sexually naive males from each line. A small number of females died between the two test series and were replaced with sexually naive counterparts. Sexually experienced and sexually naive subjects in the experimental-chamber tests responded similarly, and, therefore, their data were combined.

\section{Apparatus}

For the home-cage tests, the male birds remained in their battery cages in the colony room. The cages were made of metal and were $14.0 \mathrm{~cm}$ high $\times 22.5 \mathrm{~cm}$ wide $\times 33.0 \mathrm{~cm}$ deep. A food tray was positioned in front of each row of cages, and a water spout was accessible through a hole in the back wall.

For the experimental-chamber tests, the animals were moved from their home cages to test arenas that consisted of two compartments: a large area $(100 \mathrm{~cm}$ high $\times 83 \mathrm{~cm}$ wide $\times 120 \mathrm{~cm}$ long $)$ in which a male was placed, and a smaller adjacent compartment $(32 \mathrm{~cm}$ high $\times 22 \mathrm{~cm}$ wide $\times 30 \mathrm{~cm}$ long) in which a female was housed. The female compartment was centered along one of the side walls of the large chamber. The four walls of the large chamber were made of plywood and painted white. Thin nylon mesh covered the top of the chamber. The nylon mesh was invisible to the video camera, which was suspended $1.5 \mathrm{~m}$ above the chamber. The floor was made of white wire mesh with white butcher paper below. A small sliding door $(25 \times 28 \mathrm{~cm})$ with a narrow window $(1.3 \mathrm{~cm}$ wide $\times 22.9 \mathrm{~cm}$ high) separated the male and female compartments.

\section{Procedure}

Home-cage tests. Male quail from the LTI, STI, HSR, and LSR lines $(n s=8)$ were tested for copulatory behavior in their home cages. The tests were conducted between 1300 and $1600 \mathrm{~h}$ Central European Time. The copulation partners were always females of the same line as the males. Since copulatory behavior typically improves with practice (Domjan, Lyons, North, \& Bruell, 1986), 10 copulation tests were conducted with each subject. This enabled us to compare the rates of improvement in the four genetic lines.
Before each trial, the food tray in front of the cages was removed to provide an unobstructed view into the cage. A trial began when a female was gently placed inside the male's home cage. The subjects were tested in random order and were paired with a different female on each trial. Behavioral observations were made for $5 \mathrm{~min}$ by an experimenter sitting $1 \mathrm{~m}$ directly in front of the cage.

A male quail initiates sexual activity by using its beak to grab and hold the head or neck feathers of the female. This behavior stimulates the receptive female to squat and be mounted by the male. Once the male has both feet on the female's back, it arches its back and moves its cloaca in contact with that of the female, making several cloacal thrusts. The latency to grab, mount, and make a cloacal contact movement was measured, along with the number of grabs, mounts, and cloacal contact movements. At the end of the observation period, the female was gently removed from the male's cage. The food trays were replaced after all trials for the day were completed. Each subject received one trial per day on each of 10 successive days.

Experimental-chamber tests. Four new subjects from each of the selected lines were tested in the experimental chambers, along with 4 males that previously served in the home-cage tests. The experimental chambers were located in a different building from the colony room. Each morning, the home cages of the subjects to be tested were placed on a cart and transported to the experiment room. Testing was started $1 \mathrm{~h}$ after the birds arrived in the experiment room.

A trial began when a male was gently placed in the test chamber. The first $10 \mathrm{~min}$ of the trial served as a habituation period. A female of the same line as the subject was in the side compartment during the habituation period, but the window to the female compartment was blocked by gray tape. After the habituation period, the tape on the window was removed for $10 \mathrm{~min}$ to allow measurement of the male's social proximity behavior. At the end of this 10 -min period, the door to the female compartment was opened, giving the male access to the female for $5 \mathrm{~min}$. Copulation invariably occurred during this 5 -min period. Video recordings were made of the last $5 \mathrm{~min}$ of the habituation period and the last $5 \mathrm{~min}$ of the window period before the male was permitted to copulate with the female. At the end of the trial, the male and female were gently removed from the test cage through the top of the chamber. Trials were conducted 5 days a week, between 1000 and $1700 \mathrm{~h}$, Central European Time. Each subject was tested every $3-5$ days until it had received a total of 10 trials.

Social proximity behavior was measured using computer analysis of the video recordings of the male's position in the experimental chamber relative to the window to the female compartment before the female was released. For a more detailed description of the computer-based image analysis system used, see Mills, Faure, Jones, and Clément (1990). The system enabled us to measure time spent in a target area that was one ninth of the experimental chamber and immediately in front of the window. In addition, we recorded the average distance of the male from the female window and time spent in the third of the chamber opposite the window. Copulatory responses were measured as in the home-cage tests.

The data were evaluated with repeated measures analyses of variance (ANOVAs), with trials as the within-subject variable and genetic line as the between-subject variable. Separate analyses were calculated for each response measure. Paired comparisons were made with the Newman-Keuls test. The alpha level was set at .05 for all statistical decisions.

\section{RESULTS}

\section{Home-Cage Tests}

As expected on the basis of previous research (Domjan et al., 1986), the male subjects initiated copulatory behavior faster as testing progressed in the home cages. 


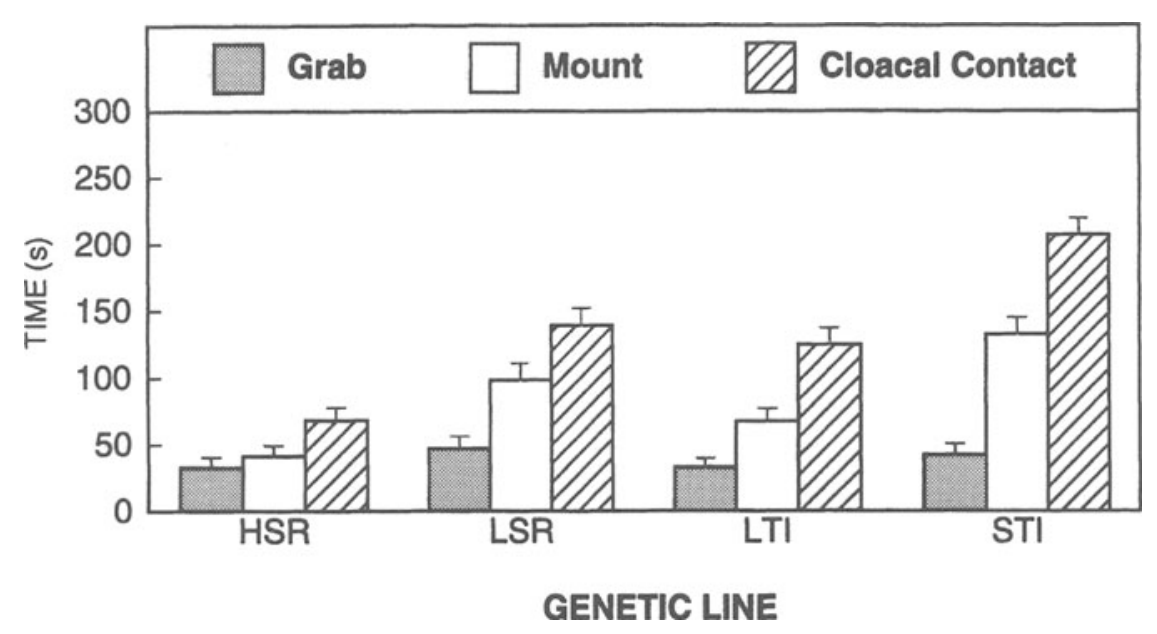

Figure 1. Mean latency (in seconds) to the first grab, mount, and cloacal contact response for each genetic line tested in the home cage. Error bars represent 1 SEM.

Latencies to grab, mount, and make cloacal contact with the female significantly declined across trials $[F \mathbf{s}(9,306)=$ $17.56,9.21$, and 8.16 , respectively]. However, these trials effects did not differ between the genetic lines. The trials $\times$ line interactions were not significant (all $F \mathbf{s}<$ 1.0 ). Therefore, the data were averaged across trials.

Figure 1 shows mean latencies to the first occurrence of each of the three sexual behaviors for each genetic line. Analysis of the latency data for the grab response failed to reveal a significant effect of line $(F<1.0)$. All groups made the grab response within a mean of $50 \mathrm{sec}$ after introduction of the female. In contrast, significant differences were found among the genetic lines in the latency to mount $[F(3,34)=4.08]$, and paired comparisons indicated that the STI subjects were slower to initiate mounting than were the HSR. Analysis of the latency to make a cloacal contact movement also revealed a significant effect of genetic line $[F(3,34)=7.05]$, and post hoc tests indicated that STI subjects took longer to initiate cloacal contact with a female than did each of the other genetic lines.

Similar findings were obtained in measures of the number of grab, mount, and cloacal contact responses. These data are summarized in Figure 2 for each genetic line averaged across trials. Grabs occurred more often than mounts or cloacal contacts. STI birds showed the most grabs per trial but made the fewest mounts and cloacal contacts. Because of this, the copulatory behavior of STI subjects was highly inefficient. They frequently started the copulatory behavior sequence by grabbing a female, but they did not consummate copulation by making cloacal contact.

To quantify the efficiency of copulatory behavior, an index was calculated by dividing the number of grabs by the number of cloacal contacts for each subject and multiplying this ratio by 10 . Scores on the copulatory effi-

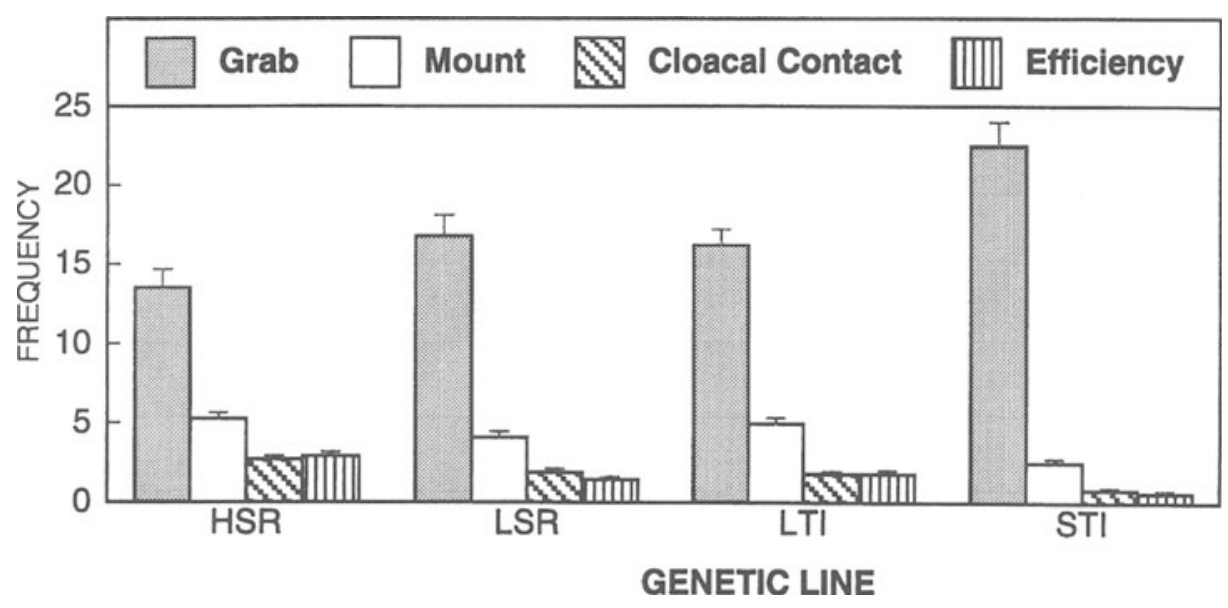

Figure 2. Mean frequency of grab, mount, and cloacal contact responses, and mean copulatory efficiency for each genetic line tested in the home cage. Error bars represent $1 S E M$. 


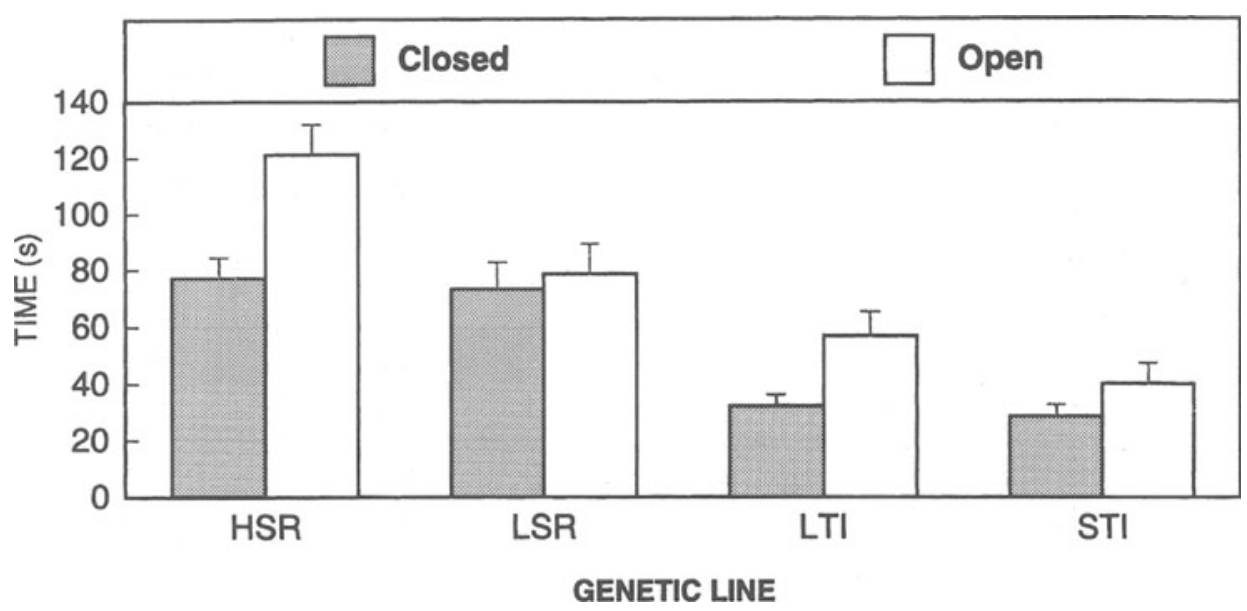

Figure 3. Mean seconds spent near the window to the female compartment for each genetic line in the experimental chambers when the window was closed and when it was open. Error bars represent $1 S E M$.

ciency index are summarized in the right set of bars in Figure 2 . The highest degree of copulatory efficiency was evident in the HSR subjects.

The number of grab, mount, and cloacal contact responses, as well as copulatory efficiency, increased significantly across trials $[F \mathrm{~s}(9,306)=3.13,2.03,3.89$, and 5.15 , respectively]. However, these changes did not differ as a function of genetic line. None of the trials $\times$ line interactions were significant (all $F \mathrm{~s}<1.0$ ). Therefore, the data were averaged across trials for each genetic line for presentation in Figure 2.

Significant main effects of genetic line were found for number of grabs $[F(3,34)=2.96]$, number of mounts $[F(3,34)=4.85]$, number of cloacal contacts $[F(3,34)=$ $5.84]$, and copulatory efficiency $[F(3,34)=7.65]$. Paired comparisons indicated that males of the STI line made significantly more grabs than did HSR subjects and significantly fewer mounts and cloacal contact movements than did HSR and LTI subjects. HSR males showed significantly higher copulatory efficiency than did each of the other groups, which did not differ among each other.

\section{Experimental-Chamber Tests}

Social proximity behavior. Social proximity behavior was measured in terms of the position of the male subjects in relation to the female's window before the female was released. These data were analyzed using an ANOVA, with genetic line as a between-subject variable and window status (open vs. closed) and trials as within-subject variables.

As in previous studies with nonselected Japanese quail (e.g., Domjan, Akins, \& Vandergriff, 1992), the males

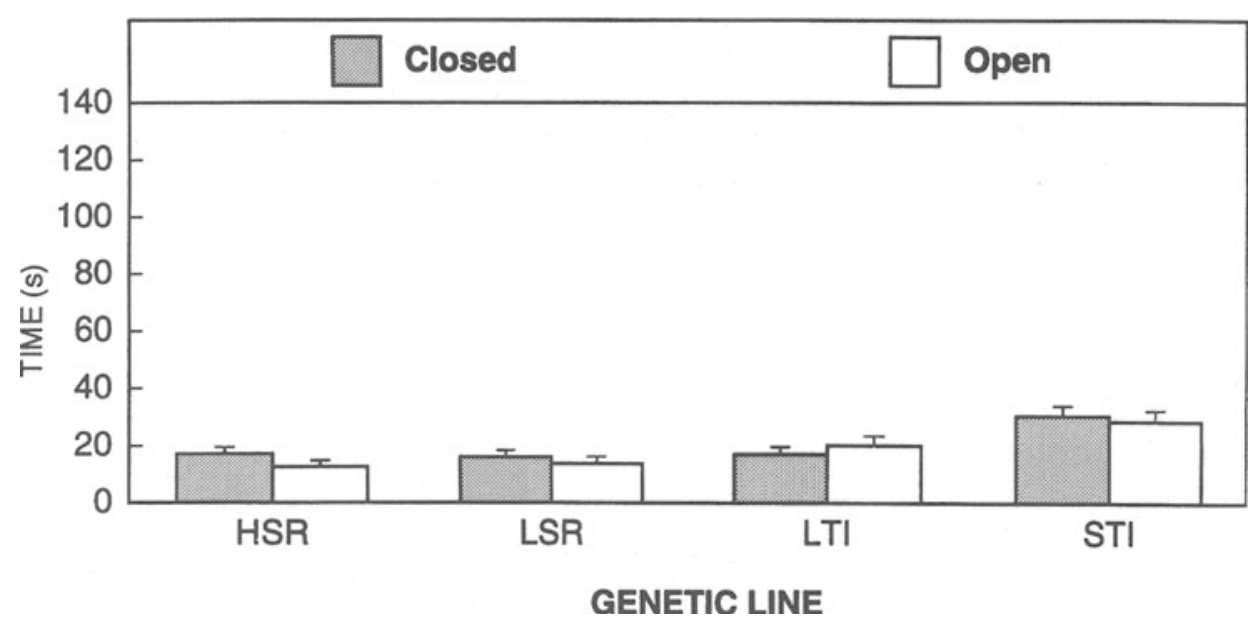

Figure 4. Mean seconds spent in the back third of the experimental chambers away from the female compartment for each genetic line when the window to the female compartment was closed and when it was open. Error bars represent 1 SEM. 


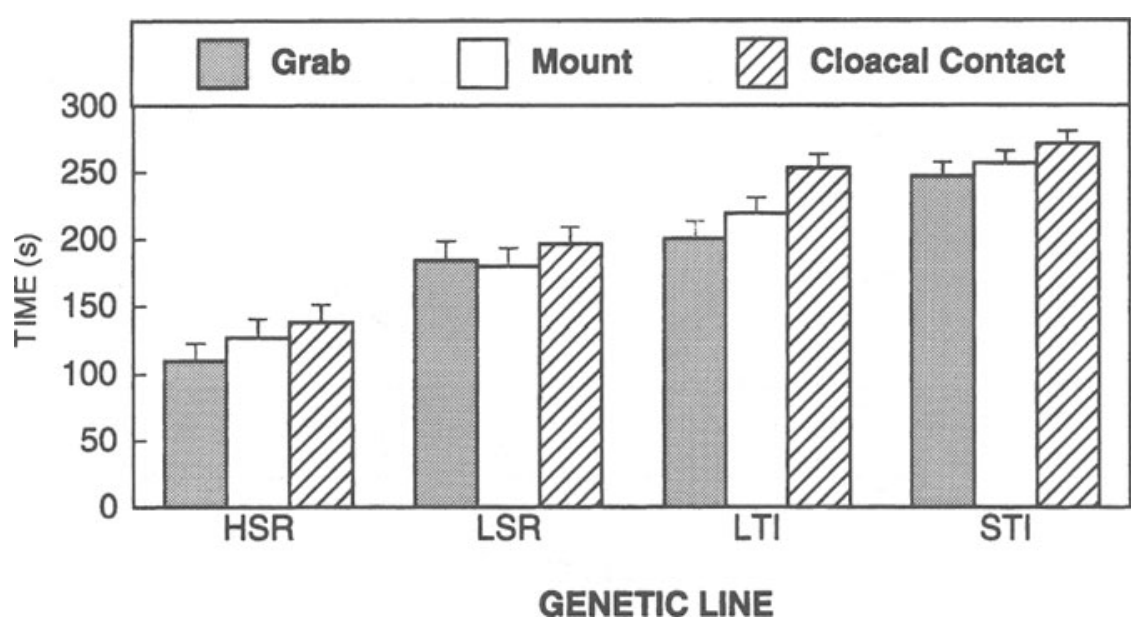

Figure 5. Mean latency (in seconds) to the first grab, mount, and cloacal contact response for each genetic line tested in the experimental chambers. Error bars represent 1 SEM.

increased their time in the zone directly in front of the female's window across trials $[F(9,324)=6.28]$. However, this effect did not interact with genetic line $[F(27,324)=$ 1.19]. Figure 3 shows time spent in the window zone for each group, combined across trials. The subjects spent more time near the window when the window was open and they could see the female on the other side than when the window was closed $[F(1,36)=5.20]$. In addition, there was a significant main effect of genetic line $[F(3,36)=$ 3.91]. Paired comparisons showed that HSR birds spent significantly more time in the window zone, close to where the female was released, than did STI and LTI birds. The interaction between window status and genetic line was not significant $(F<1.0)$.

The above results indicate that males in the HSR line showed the greatest level of social proximity behavior. This was also evident in a measure of the average dis- tance of each male bird from the female window when the window was open. This measure also showed a significant effect of genetic line $[F(3,36)=3.25]$, and paired comparisons indicated that males in the HSR line were significantly closer to the female window than were males in the STI line.

Using the computer-based trajectometer, we also measured how much time the male birds spent away from the female side of the experimental chamber by calculating time spent in the back third of the experimental chamber. These data are summarized in Figure 4. The time spent in the back of the chamber was independent of whether the window to the female compartment was open or closed $(F<1.0)$. The effects of trial and the trial $\times$ line interaction were also not significant $[F(9,27)=1.09$, and $F<$ 1.0 , respectively]. However, there was a significant effect of genetic line $[F(3,36)=3.30]$. Paired comparisons

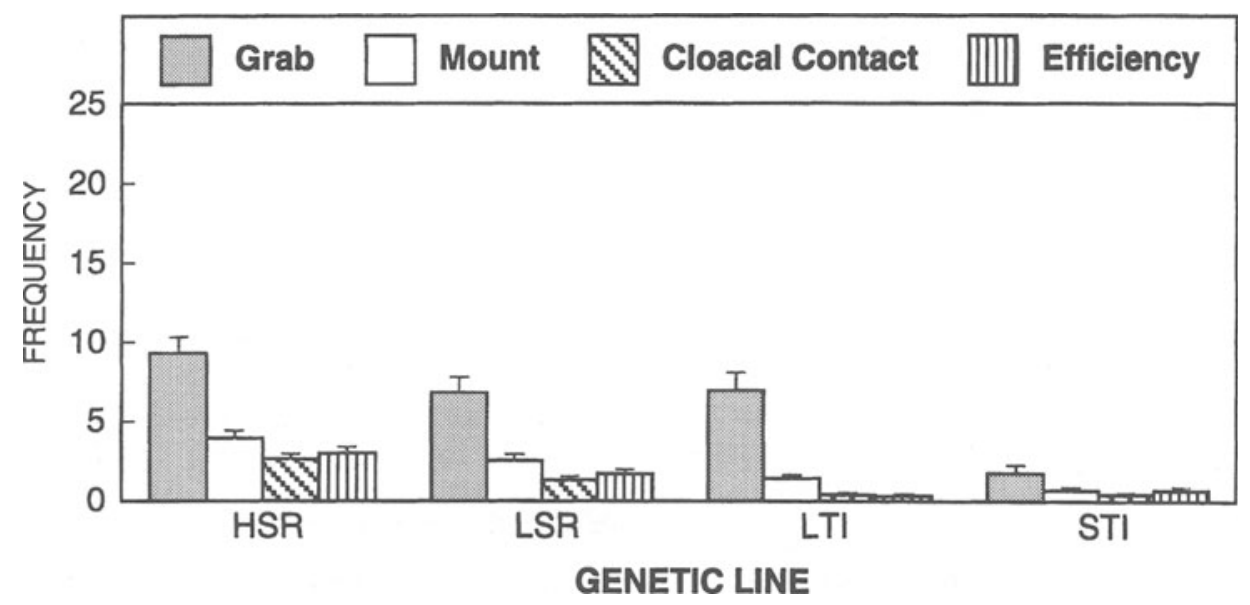

Figure 6. Mean frequency of grab, mount, and cloacal contact responses, and mean copulatory efficiency for each genetic line tested in the experimental chambers. Error bars represent $1 S E M$. 
revealed that the males in the STI line spent significantly more time in the back than did the males in the HSR and LSR lines.

Copulatory behavior. As we observed in the home cages, with repeated testing, latencies to grab, mount, and make cloacal contact decreased, and increases were observed in the frequency of grab, mount, cloacal contact responses and in copulatory efficiency. All of these main effects of trials were significant [all $F \mathrm{~s}(9,288) \geq 3.10$ ].

Figure 5 shows the mean latency of each copulatory response for each genetic line, averaged across trials. A significant main effect of genetic line was obtained for the grab, mount, and cloacal contact responses $[F \mathrm{~s}(3,32)=$ $3.16,3.20$, and 3.86, respectively]. Paired comparisons indicated that males in the HSR line had shorter latencies to grab and mount than did the STI subjects. HSR birds were also quicker to make the first cloacal contact than were both the STI birds and LTI birds.

Figure 6 shows the frequency of each sexual response and the copulatory efficiency of the four lines of quail, averaged across trials. Significant main effects of genetic line were found in the number of mounts, the number of cloacal contacts, and copulatory efficiency $\left[F_{\mathrm{s}}(3,32)=\right.$ $2.99,4.22$, and 5.95, respectively]. However, the lines did not differ significantly in the number of grabs $[F(3,32)=$ 2.12]. Paired comparisons revealed differences similar to those observed with the latency data. Specifically, HSR males mounted more frequently than did STI males and made more cloacal contact responses than did STI and LTI males. Additionally, HSR birds showed significantly greater copulatory efficiency than did STI and LTI birds.

\section{DISCUSSION}

The present findings demonstrate that genetic selection based on inherent fearfulness and social reinstatement exhibited during the first 10 days after hatching influences the behavior of quail in adulthood. Significant differences in social proximity behavior and copulatory behavior were obtained between the selected lines. Evidently genetic selection, in these lines, influences a greater range of behaviors than those directly selected for, and these effects are evident in animals that are older than those used in previous experiments (reviewed in Mills et al., 1994).

Behavior early in life is not always predictive of later performance. For example, Nol, Cheng, and Nichols (1996) found that dominance rankings of quail are not stable during ontogenetic development. Such developmental discontinuities make examples of continuity particularly noteworthy. Consistent with the present findings, Jones et al. (1994) reported that genetic lines selected on the basis of TI during the first week after hatching (STI and LTI lines) continue to show corresponding differences in TI and response to restraint at 70-75 days of age. Similar findings were reported by Launay, Mills, and Faure (1993), who showed that genetic differences in social reinstatement behavior also persist through the first 70 days of life.
The differences in sexual behavior observed in the present study extend the effects of the present genetic selection to new measures of behavior. Previous studies have shown that genetic selection based on duration of TI results in corresponding differences in other measures of fear, including freezing, vocalization, locomotion in an open field, and emergence from a hole-in-the-wall box (Jones et al., 1991). In an analogous fashion, genetic selection based on the treadmill test has been found to produce differences in other measures of social behavior, such as social proximity behavior, peeping (Launay et al., 1991) and physiological and behavioral responses to social separation (Mills et al., 1993). The present findings indicate that genetic selection also influences various measures of male sexual behavior.

The effects on sexual behavior are of particular interest because they show that genetic selection based on responding during the first 10 days after hatching can affect responses that are not in the repertoire of the animals at the time of selection. The present genetic effects on appetitive or social proximity behavior show that the line effects are not limited to unconditioned copulatory responses elicited by the presence of a female quail. Social proximity behavior reflects sexual learning (see Domjan et al., 1992; Domjan \& Hall, 1986). Therefore, the results with social proximity behavior suggest that genetic selection for fearfulness and social reinstatement behavior influenced the vigor of conditioned sexual responses. These effects on conditioned sexual behavior may have reflected genetic differences in sexual learning and/or genetic differences in the motivation to perform sexually conditioned responses.

Blohowiak and Siegel (1984) previously reported a genetic basis for copulatory behavior in male quail, on the basis of data from lines selected for high and low mating frequency. The present results indicate that the genetic selection criterion need not include a measure of copulatory behavior. Selection based on sociality and fearfulness can also result in lines differing in copulatory behavior.

Of the four groups tested, Group HSR (high social reinstatement) and Group STI (short tonic immobility, low inherent fearfulness) showed the greatest differences in behavior. Generally, Group HSR showed more vigorous sexual behavior (greater social proximity behavior, shorter latencies to copulate, larger numbers of copulatory responses, and greater copulatory efficiency) than did Group STI. (The only exception to this generalization was in the number of grab responses observed in the home-cage tests, which will be discussed later.) The fact that Group HSR generally showed the most vigorous sexual behavior was expected given that sociality is compatible with (and perhaps even conducive to) sexual behavior. However, we did not expect the least vigorous sexual behavior to be evident in Group STI.

The genetic selection was carried out in such a way that selection for STI or LTI was weighted for independence from social reinstatement behavior, and selection for HSR or LSR was weighted for independence from du- 
ration of TI (Mills \& Faure, 1991). Selection for short durations of TI in Group STI presumably resulted in a line of birds of low inherent fearfulness but of intermediate sociality. Given the presumed low levels of fearfulness in the STI line, the low sexual performance of this group was an unexpected finding. Since high levels of fear have an inhibitory influence on many different forms of behavior (Jones, 1987a), we expected Group LTI to show the lowest levels of sexual behavior, because, presumably, they were most likely to experience fear induced by the sexual partner and/or other aspects of the test procedures.

One possible reason for the poor sexual performance of Group STI is that the low inherent fearfulness of these birds made them generally less attentive to changes in their environment and therefore less attentive to the release of the female. However, contrary to a generalized inattention hypothesis, Group STI made significantly more grab responses than did Group HSR when tested in the home cages. In addition, the shift from the home cages to the experimental chamber increased the latency of copulation for Group STI, indicating that Group STI was not deficient in reacting to this change in the test context.

The birds were more responsive to a female during tests in their home cage than during tests in the experimental chamber. Latencies to copulate were considerably longer in the experimental chamber, and fewer copulatory responses occurred in the experimental chambers than in the home cages. Similar disruptive effects of relative context novelty on sexual behavior have been reported by other investigators (Crawford, Akins, \& Domjan, 1994; Deviche \& Schumacher, 1982). One possible interpretation of the previously published effects is that relative novelty elicits fear responses that interfere with, and hence inhibit, copulatory behavior. However, if this were the case, Group LTI should have shown the lowest levels of copulatory behavior in the experimental chamber rather than Group STI. The failure to obtain this effect suggests that other factors may be responsible for the effects of test context on sexual behavior. One possibility, suggested by Crawford et al. (1994), is that context effects are related to the fact that male quail are territorial during the breeding season.

The low level of sexual performance in birds selected for low fearfulness (Group STI) has several implications. One implication is that selection pressures that favor increased fearfulness (Thompson et al., 1981) will not necessarily result in lower levels of sexual behavior. A second implication is that some degree of fear is conducive to sexual performance. Consistent with this suggestion, several investigators have reported that copulatory behavior in rats is facilitated by increased arousal caused by cutaneous shock or handling (Barfield \& Sachs, 1968; Caggiula \& Eibergen, 1969; Larsson, 1963; Sachs \& Barfield, 1974). However, the mechanisms whereby fearfulness and fear may facilitate sexual behavior remain to be identified.

Finally, although the present observations focused on the behavior of male quail, some of the group differences that occurred may have been mediated by the behavior of the females. Each male was always tested with a female of its own genetic line. Therefore, genetic differences among the males were accompanied by corresponding differences among the females. Additional research is required to determine to what extent differences in the copulatory behavior of the males selected for STI and HSR behavior were due to possible differences in the receptivity of the STI and HSR females. It is of interest to note in this context that, in the Japanese quail, unlike most gallinaceous species, the female is larger than the male (see Mills, Crawford, Domjan, \& Faure, 1997), and it is possible that STI males were unable to dominate the relatively fearless females of their own line.

\section{REFERENCES}

BARFIELD, R. J., \& SACHS, B. D. (1968). Sexual behavior: Stimulation by painful electrical shock to skin in male rats. Science, 161, 392-393.

BLACKMAN, D. (1977). Conditioned suppression and the effects of classical conditioning on operant behavior. In W. K. Honig \& J. E. R. Staddon (Eds.), Handbook of operant behavior (pp. 340-363). Englewood Cliffs, NJ: Prentice-Hall.

B Lohowiak, C. C., \& Siegel, P. B. (1984). Long-term selection for mating frequency in male Japanese quail. Zeitschrift für Tierzüchtung und Züchtungsbiologie, 100, 338-349.

Bult, J. A., III, \& Overmier, J. B. (1968). Additive and subtractive properties of excitation and inhibition. Journal of Comparative \& Physiological Psychology, 66, 511-514.

Caggiula, A. R., \& Eibergen, R. (1969). Copulation of virgin male rats evoked by painful peripheral stimulation. Journal of Comparative \& Physiological Psychology, 69, 414-419.

Crawford, L. L., Akins, C. K., \& Domjan, M. (1994). Stimulus control of copulatory behavior in sexually naive male Japanese quail (Coturnix japonica): Effects of test context and stimulus movement. Journal of Comparative Psychology, 108, 252-261.

Davis, H. (1968). Conditioned suppression: A survey of the literature. Psychonomic Monograph Supplements, 2(14, Whole No. 30), 283-291.

Deviche, P., \& SCHUMACHER, M. (1982). Behavioural and morphological dose-responses to testosterone and to $5 \alpha$-dihydrotestosterone in the castrated male Japanese quail. Behavioural Processes, 7, 107121.

Dickinson, A., \& Dearing, M. F. (1979). Appetitive-aversive interactions and inhibitory processes. In A. Dickinson \& R. A. Boakes (Eds.), Mechanisms of learning and motivation (pp. 203-231). Hillsdale, NJ: Erlbaum.

Domjan, M., AkIns, C., \& VANDergriff, D. H. (1992). Increased responding to female stimuli as a result of sexual experience: Tests of mechanisms of learning. Quarterly Journal of Experimental Psychology, 45B, 139-157.

Domjan, M., \& HaLl, S. (1986). Determinants of social proximity in Japanese quail (Coturnix coturnix japonica): Male behavior. Journal of Comparative Psychology, 100, 59-67.

Domjan, M., Lyons, R., North, N. C., \& Bruell, J. (1986). Sexual Pavlovian conditioned approach behavior in male Japanese quail (Coturnix coturnix japonica). Journal of Comparative Psychology, $100,413-421$.

DOMJAN, M., \& NASH, S. (1988). Stimulus control of social behavior in male Japanese quail (Coturnix coturnix japonica). Animal Behaviour, 36, 1006-1015.

FAURE, J. M. (1975). Étude des liaisons entre comportement en openfield et émotivité chez le jeune poussin [A study of the relations between open-field behavior and emotionality in the young chick]. Annales de génétique et selection animal, 7, 197-204.

FAuRe, J. M., Jones, R. B., \& Bessei, W. (1983). Fear and social motivation as factors in open-field behavior of the domestic chick: A theoretical consideration. Biology of Behavior, 8, 103-116.

GalluP, G. G., JR. (1979). Tonic immobility as a measure of fear in domestic fowl. Animal Behaviour, 27, 316-317. 
GraY, J. A. (1971). The psychology of fear and stress. London: Weidenfield \& Nicholson.

JONES, R. B. (1986). The tonic immobility reaction of the domestic fowl: A review. World's Poultry Science Journal, 42, 82-96.

JONES, R. B. (1987a). The assessment of fear in the domestic fowl. In R. Zayan \& I. J. H. Duncan (Eds.), Cognitive aspects of social behavior in the domestic fowl (pp. 40-81). Amsterdam: Elsevier.

JONES, R. B. (1987b). The assessment of fear in laying hens: Correlational analysis of methods and measures. British Poultry Science, 28, 319-326

JoNes, R. B., \& Mills, A. D. (1983). Estimation of fear in two lines of the domestic chick: Correlations between various methods and measures. Behavioural Processes, 8, 243-253.

Jones, R. B., Mills, A. D., \& FAURE, J. M. (1991). Genetic and experiential manipulation of fear-related behavior in Japanese quail (Coturnix coturnix japonica). Journal of Comparative Psychology, 105, 15-24.

Jones, R. B., Mills, A. D., Faure, J. M., \& Williams, J. B. (1994). Restraint, fear, and distress in Japanese quail genetically selected for long or short tonic immobility reactions. Physiology \& Behavior, 56, 529-534.

LARSSON, K. (1963). Non-specific stimulation and sexual behaviour in the male rat. Behaviour, 20, 110-114.

LaUnAY, F., Mills, A. D., \& FAURE, J. M. (1991). Social motivation in Japanese quail Coturnix coturnix japonica chicks selected for high or low levels of treadmill behaviour. Behavioural Processes, 24, 95-1 10.

Launay, F., Mills, A. D., \& Faure, J. M. (1993). Effects of test age, line and sex on tonic immobility responses and social reinstatement behaviour in Japanese quail Coturnix japonica. Behavioural Processes, 29, 1-16.

Mills, A. D., Crawford, L. L., Domjan, M., \& Faure, J. M. (1997). The behavior of the Japanese or domestic quail, Coturnix japonica. Neuroscience \& Biobehavioral Reviews, 21, 261-281.

MilLs, A. D., \& FAURE, J. M. (1986). The estimation of fear in domestic quail: Correlations between various methods and measures. Biology of Behavior, 11, 235-243.

MiLLS, A. D., \& FAURE, J. M. (1990). The treadmill test for the measurement of social motivation in Phasianidae chicks. Medical Science Research, 18, 179-180.
Mills, A. D., \& Faure, J. M. (1991). Divergent selection for duration of tonic immobility and social reinstatement behavior in Japanese quail (Coturnix coturnix japonica) chicks. Journal of Comparative Psychology, 105, 25-38.

Mills, A. D., Faure, J. M., Jones, R. B., \& Clément, P. (1990). Trajectometric analysis of open-field behavior in Japanese quail chicks (Coturnix japonica). Biology of Behavior, 15, 183-195.

Mills, A. D., Jones, R. B., Faure, J. M., \& Williams, J. B. (1993). Responses to isolation in Japanese quail genetically selected for high or low sociality. Physiology \& Behavior, 53, 183-189.

Mills, A. D., Launay, F., Turro, I., Jones, J. B., Williams, J. B., \& FAURE, J. M. (1994). Sélection divergente sur la peur et la sociabilité chez la caille japonaise Coturnix japonica. Réponses et conséquences [Divergent selection for fear and sociality in the Japanese quail $\mathrm{Co}$ turnix japonica: Responses and consequences.]. In M. Picard, R. H. Porter, \& J. P. Signoret (Eds.), Comportement et bien-être animal (pp. 127-139). Paris: INRA Publications.

NoL, E., Cheng, K., \& Nichols, C. (1996). Heritability and phenotypic correlations of behaviour and dominance rank of Japanese quail. $A n$ imal Behaviour, 52, 813-820.

RESCORLA, R. A., \& Solomon, R. L. (1967). Two-process learning theory: Relationships between Pavlovian conditioning and instrumental learning. Psychological Review, 74, 151-182.

SACHS, B. D., \& BARFIELD, R. J. (1974). Copulatory behavior of male rats given intermittent electric shocks: Theoretical implications. Journal of Comparative \& Physiological Psychology, 86, 607-615.

Suarez, S. D., \& Gallup, G. G., JR. (1981). Predatory overtones of open-field testing in chickens. Animal Learning \& Behavior, 9, 153 163.

Thompson, R. K. R., Foltin, R. W., Boylan, R. J., Sweet, A., Graves, C. A., \& Lowitz, C. E. (1981). Tonic immobility in Japanese quail can reduce the probability of sustained attack by cats. Animal Learning \& Behavior, 9, 145-149.

(Manuscript received October 27, 1997; revision accepted for publication February 19, 1998.) 